\section{Kidney \\ Blood Pressure Research}

Kidney Blood Press Res 2018;43:191-205

DOI: 10.1159/000487501

Published online: February 21, 2018

Accepted: February 8, 2018

This article is licensed under the Creative Commons Attribution-NonCommercial-NoDerivatives 4.0 InternaThis article is licensed under the Creative Commons Attribution-NonCommercial-NoDerivatives 4.0 Interna-
tional License (CC BY-NC-ND) (http://www.karger.com/Services/OpenAccessLicense). Usage and distribution for commercial purposes as well as any distribution of modified material requires written permission.

\title{
The Association Between Oxidative Stress Alleviation via Sulforaphane-Induced Nrf2- HO-1/NQO-1 Signaling Pathway Activation and Chronic Renal Allograft Dysfunction Improvement
}

\author{
Daoyuan Lva,b Qin Zhou a,b Yue Xiaa,b Xu You,a,b Zhihong Zhao ${ }^{\mathrm{a}}$ \\ Yongqiang Li $i^{a, b}$ Hequn Zou ${ }^{a, b}$
}

\begin{abstract}
aSouthern Medical University, Guangzhou, bDepartment of Nephrology, Institution of Urology and Nephrology, the Third Affiliated Hospital of Southern Medical University, Guangzhou, 'Department of Clinical Laboratory, the Third Affiliated Hospital of Southern Medical University, Guangzhou, dDepartment of Nephrology, Shenzhen People's Hospital, Shenzhen, China
\end{abstract}

\section{Key Words}

Chronic renal allograft dysfunction • Oxidative stress $\bullet$ Nrf2 - Sulforaphane

\begin{abstract}
Background/Aims: Chronic renal allograft dysfunction (CRAD) is a leading cause of long-term renal allograft loss. Oxidative stress may account for the nonspecific interstitial fibrosis and tubular atrophy that occur in CRAD. An antioxidant intervention via Nrf2 signaling pathway activation might be a promising therapy for some kidney diseases. The present paper investigates whether there is an association between oxidative stress alleviation via sulforaphane-induced Nrf2-HO-1/NQO-1 signaling pathway activation and CRAD improvement. Methods: F344 rat kidneys were orthotopically transplanted into Lewis rat recipients to establish CRAD models. Sulforaphane was administered at $1.5 \mathrm{mg} / \mathrm{kg}$ intraperitoneally once daily. Renal function and 24-hour urinary protein were monitored for variations for 24 weeks after transplantation. After 24 weeks, renal histopathology was evaluated according to the Banff criteria after hematoxylin and eosin, Masson's trichrome and periodic acid-Schiff stainings. Additionally, intrarenal oxidative stress was assessed by the indicators malondialdehyde, 8-isoprostane, oxidizedlow density lipoprotein and 8-hydroxy-2'-deoxyguanosine, as well as the activity levels of the antioxidant enzymes total superoxide dismutase, catalase, glutathione peroxidase, glutathione reductase and $\gamma$-glutamylcysteine synthetase. Nrf2, $\mathrm{HO}-1$ and NQO-1 expression levels were determined via immunohistochemical and Western blot analyses. Results: The sulforaphane-induced Nrf2-HO-1/NQO-1 signaling pathway activation, as demonstrated by
\end{abstract}




\section{Kidney Blood Pressure Research}

Kidney Blood Press Res 2018;43:191-205

\begin{tabular}{l|l}
\hline DOI: 10.1159/000487501 & (c) 2018 The Author(s). Published by S. Karger AG, Basel
\end{tabular}

Published online: February 21, 2018 www.karger.com/kbr

Lv et al.: The Association Between Oxidative Stress Alleviation and Chronic Renal

Allograft Dysfunction Improvement

immunohistochemical and Western blot analyses, delayed the progression of serum creatinine and blood urea nitrogen, particularly lowering the 24-hour urinary protein levels of CRAD. The semi-quantified histopathological changes were also alleviated. Evidence of oxidative stress alleviation, as indicated by a concurrent decrease in the indicators and sustained levels of antioxidant enzymes activity, was found in the renal allografts after sulforaphane intervention. Conclusion: Oxidative stress alleviation caused by continuous sulforaphane-induced Nrf2HO-1/NQO-1 signaling pathway activation is associated with functional and morphological improvements of CRAD.

\section{Introduction}

Currently, kidney transplantation is the preferred treatment for patients with end-stage renal disease. Available data recently revealed that up to 17,814 adult kidney transplants were performed in the US in 2014, while 19, 426 transplants were performed in Europe in 2013 and 7, 131 transplants were performed in China in 2015 [1,2]. Due to improvements in surgical techniques, the introduction of novel immunosuppressants and better postoperative care, the 1-year survival rate associated with renal allografts has increased from $50 \%$ to $90-97.3 \%$ over the past 20 years [1, 3-5]. However, no corresponding improvement in the long-term survival rate of renal allografts has occurred. One of the leading causes of late renal allografts loss is chronic renal allograft dysfunction (CRAD) [6], which was also known as "chronic allograft nephropathy" prior to the Banff '05 meeting [7]. CRAD is characterized by progressive kidney dysfunction and morphological deterioration occurring at least 3-6 months after transplantation [8]. Recent studies have suggested that nonspecific interstitial fibrosis and tubular atrophy (IF/TA) might play crucial roles in causing CRAD rather than immune and non-immune factors [9-11]. Unfortunately, the exact mechanism and the optimal treatment for nonspecific IF/TA in CRAD remain unclear. Emerging evidence suggests that oxidative stress could be an underlying mechanism of nonspecific IF/TA.

The nuclear factor erythroid 2-related factor 2 (Nrf2) signaling pathway is one of the most pivotal pathways of the cellular defense system. This pathway regulates the transcription of numerous antioxidant and cytoprotective genes that can counteract oxidative stress. Nrf2 acts when it is released from its repressive cytosolic protein, Kelch-like ECHassociated protein 1 (Keap1), and translocates into the nucleus [12]. Nrf2 signaling pathway activation has recently shown potential for defending against oxidative stress-associated kidney disorders, such as acute kidney injury and diabetic nephropathy [12]. Sulforaphane (SFN) is a natural Nrf2 activator derived from cruciferous vegetables; SFN contains a sulfur motif, which can lead to Keap1 sulfhydryl modification and ultimately Nrf2 activation [13]. We speculated that oxidative stress is involved in the progression of CRAD and that there may be an association between suppressing oxidative stress through activating Nrf2 along with its downstream antioxidant proteins, heme oxygenase-1 (HO-1) and NAD(P)H quinone oxidoreductase-1 (NQO-1), and CRAD improvement. Hence, this study used a 24-week-long, continuous SFN intervention in a rat model of CRAD to explore whether the alleviation of oxidative stress via activating the Nrf2-HO-1/NQO-1 signaling pathway by SFN induces functional and morphological improvements of the renal allografts.

\section{Materials and Methods}

\section{Animals}

Male inbred strain F344 and Lewis rats, all weighing between $280 \mathrm{~g}$ and $320 \mathrm{~g}$, were purchased from Beijing Vital River Laboratory Animal Technology Co., Ltd., China. All rats were housed under standard conditions and fed rat chow and water ad libitum. The study protocol was approved by the Institutional 


\section{Kidney Blood Pressure Research}

Kidney Blood Press Res 2018;43:191-205

\begin{tabular}{l|l}
\hline DOI: 10.1159/000487501 & (C) 2018 The Author(s). Published by S. Karger AG, Basel
\end{tabular}

Published online: February 21, $2018 \quad$ www.karger.com/kbr

Lv et al.: The Association Between Oxidative Stress Alleviation and Chronic Renal

Allograft Dysfunction Improvement

Animal Care and Use Committee of Southern Medical University and the Ethics Committee of the Third Affiliated Hospital of Southern Medical University.

\section{Kidney Transplantation}

Rats were anesthetized by $2 \%$ pentobarbital sodium at $3 \mathrm{ml} / \mathrm{kg}$ body weight via a single intraperitoneal injection. The left kidney of each donor F344 rat was isolated, perfused with approximately $10 \mathrm{ml}$ of $4^{\circ} \mathrm{C}$ Ringer's solution, excised and transplanted orthotopically into weight-matched Lewis rat recipient after excision of the native kidney. The renal arteries, veins and ureters of the donor and recipient were anastomosed end-to-end with 11-0 Prolene sutures. The total ischemia time of the renal allografts ranged from 25 to 40 minutes. After transplantation, ceftriaxone sodium (Rocephin, F. Hoffmann-La Roche AG, Switzerland) was injected intraperitoneally at $1.5 \mathrm{mg} / \mathrm{kg}$ body weight for 3 days to prevent infection, while cyclosporine (Sandimmune, Novartis Pharma Stein AG, Switzerland) was injected subcutaneously at $1.5 \mathrm{mg} /$ $\mathrm{kg}$ body weight for 10 days to prevent acute rejection. 10 days after transplantation, the contralateral native kidney of the Lewis recipient was excised and the condition of the left transplanted kidney was checked. Rats with any signs of unsuccessful transplantation were excluded from further analyses and sacrificed.

\section{Experimental Design}

All rats were divided into 4 groups: Group A (n=10): the unilateral nephrectomy control group, in which right nephrectomies were performed on Lewis rats; Group B $(n=10)$ : the unilateral nephrectomy control group, in which right nephrectomies were performed on F344 rats; Group C ( $\mathrm{n}=10)$ : the CRAD group, in which F344 donor kidneys were transplanted into Lewis recipients according to the above procedure; and Group D ( $\mathrm{n}=10)$ : the CRAD+SFN group, in which SFN (Eykiys Research Biological Technology, China) was dissolved in normal saline and injected intraperitoneally at $1.5 \mathrm{mg} / \mathrm{kg}$ body weight into CRAD rats once daily. All groups underwent the same anesthesia, anti-infection and anti-rejection protocols described above. All rats were observed for 24 weeks post operation before being sacrificed.

\section{Functional Studies}

The general status, including body weight, of all rats was recorded once every 4 weeks. At 8, 12, 16, 20 and 24 weeks, blood sample (1-2 ml) was obtained from the angular vein of each rat with a 20 - $\mu$ l glass capillary tube after the rat had fasted for 12 hours. Rats were housed in individual metabolic cages for 24 hours to collect and calculate the volume of urine samples. The blood and urine samples were centrifuged at $4^{\circ} \mathrm{C}$, and the serum creatinine (SCr), blood urea nitrogen (BUN) and 24-hour urinary protein (24 h-Pro) levels were measured using an automatic biochemical analyzer (F. Hoffmann-La Roche AG, Switzerland).

\section{Harvesting}

At 24 weeks, all rats were sacrificed and their renal tissues were collected. After in situ perfusion with $4^{\circ} \mathrm{C}$ Ringer's solution, representative portions of the renal tissues were fixed with $4 \%$ paraformaldehyde for 36-48 hours for subsequent histopathological and immunohistochemical analyses. The remaining tissues were snap-frozen in liquid nitrogen and stored at $-80^{\circ} \mathrm{C}$ for oxidative stress assessment and Western blot analysis.

\section{Histopathology}

After the paraformaldehyde-fixed renal tissues were embedded in paraffin, 2- $\mu$ m-thick sections were prepared using a microtome. After rehydration, sections were stained with hematoxylin and eosin (H\&E), Masson's trichrome and periodic acid-Schiff (PAS) stainings to evaluate lesions affecting the glomeruli, tubules, interstitium and vessels by light microscopy. The degree of renal histopathological changes was scored semi-quantitatively on a scale from 0 to $3+$ for glomerulopathy, TA, interstitial cellular infiltration with fibrosis and arterial intimal fibroplasia using the Banff criteria [7, 14]. The total Banff score $(0-12+)$ of each sample was judged independently by 2 pathologists who were blind to the grouping information.

Oxidative Stress Assessment

Oxidative Stress Indicators. To determine the levels of intrarenal oxidative stress, the following indicators of the renal tissues were assessed at 24 weeks: malondialdehyde (MDA), 8-isoprostane, oxidized- 


\section{Kidney Blood Pressure Research}

Kidney Blood Press Res 2018;43:191-205

\begin{tabular}{l|l}
\hline DOI: 10.1159/000487501 & (c) 2018 The Author(s). Published by S. Karger AG, Basel
\end{tabular}

Published onlıne: February 21, 2018 www.karger.com/kbr

low density lipoprotein (ox-LDL) and 8-hydroxy-2'-deoxyguanosine (8-OHdG). MDA was measured using a thiobarbituric acid reaction kit, while 8-isoprostane, ox-LDL and 8-OHdG were measured using the respective rat tissue-specific enzyme-linked immunosorbent assay kits.

Antioxidant Enzymes. To evaluate the antioxidant defenses to better delineate the oxidative stress status in the kidney, the intrarenal activity levels of the antioxidant enzymes total superoxide dismutase (SOD), catalase (CAT), glutathione peroxidase (GPx), glutathione reductase (GR) and $\gamma$-glutamylcysteine synthetase $(\gamma$-GCS) were determined using commercial kits. All of the abovementioned kits were purchased from the Jiancheng Bioengineering Institute, Nanjing, China, and the assays were performed in accordance with the manufacturer's instructions.

\section{Immunohistochemistry}

Paraffin-embedded 4- $\mu \mathrm{m}$-thick sections were prepared for the immunohistochemical analysis. After routine deparaffinization and rehydration, antigen retrieval was performed by boiling $0.01 \mathrm{M}$ citrate buffer in an autoclave for 3 minutes. After cooling to ambient temperature, the endogenous peroxidases were blocked by $3 \%$ hydrogen peroxide. Target sections were incubated with (i) anti-Nrf2 antibody (Abcam, USA, 1:500 dilution in PBS, v/v), (ii) anti-HO-1 antibody (Abcam, USA, 1:200 dilution in PBS, v/v) and (iii) antiNQO-1 antibody (Abcam, USA, 1:300 dilution in PBS, v/v) respectively at $4{ }^{\circ} \mathrm{C}$ overnight. The following main steps were secondary antibody incubation, diaminobenzidine coloration and hematoxylin counterstaining. In total, to every target protein, 20 randomly discontinuous fields containing glomeruli, tubules, interstitium and vessels from 2 different representative sections of each renal tissue sample were observed and analyzed by light microscopy. Images were captured using an upright microscope with a camera (BX51, OLYMPUS Corporation, Japan), and a semi-quantitative analysis was then performed with Image-Pro Plus 6.0 software (Media Cybernetics, USA). The integrated optical density (IOD) value and the measurement area of each image were calculated. The level of the target protein expression was represented by value of IOD/Area.

\section{Western Blot Analysis}

Total and nuclear protein lysates of the renal tissues were prepared according to the manuals of the commercial kits (KeyGEN Biotech, China). After separation by sodium dodecyl sulfate polyacrylamide gel electrophoresis ( $12 \%$ separation gel), proteins were transferred electrophoretically ( $200 \mathrm{~mA}, 90$ minutes) to polyvinylidene difluoride membranes. Then, $5 \%$ bovine serum albumin (BSA) was used at ambient temperature for 1 hour to block nonspecific binding. Target membranes were incubated with (i) anti-Nrf2 antibody (1:500 dilution in 5\% BSA, v/v), (ii) anti-HO-1 antibody (1:1000 dilution in 5\% BSA, v/v) and (iii) anti-NQO-1 antibody (1:1000 dilution in $5 \% \mathrm{BSA}, \mathrm{v} / \mathrm{v})$ respectively at $4^{\circ} \mathrm{C}$ overnight. The internal control of the total and nuclear proteins were $\beta$-actin (antibody from CoWin Biosciences, China, 1:1000 dilution in 5\% BSA, v/v) and histone H3 (antibody from Beyotime Biotechnology, China, 1:1000 dilution in 5\% BSA, v/v). The next day, the membranes were incubated for 1-2 hours at ambient temperature with the corresponding secondary antibody (CoWin Biosciences, China, 1:5000 dilution in 5\% BSA, v/v). The results were visualized by enhanced chemiluminescence signals captured using a digital visualizer (Eastman Kodak Company, USA). Each renal tissue sample was tested in triplicate. The IOD values of the target bands and the internal control bands ( $\beta$-actin or histone H3) were calculated by Image-Pro Plus 6.0 software. The level of target protein expression was represented by the IOD value ratio of the target band to the internal control band.

\section{Statistical Analysis}

Statistical analyses were performed using SPSS 20.0 software (IBM Corporation, USA). Data are presented as the means \pm standard deviations (SDs). Differences between groups were assessed by using a one-way analysis of variance (ANOVA). Least significant difference (equal variances assumed) or Dunnett's T3 (equal variances not assumed) tests were conducted for multiple comparisons after ANOVA. Significant differences were inferred at $\mathrm{P}<0.05$. 


\section{Kidney Blood Pressure Research}

\section{Results}

\section{Functional Changes}

General Status and Body Weight. Neither serious infections nor acute rejections occurred during the observation period. All 40 rats in the 4 groups were included in the final analyses. As shown in Fig. 1(a), rats in all 4 groups showed steady weight gain over time. No significant differences in body weight were found between Groups C and D, indicating that long-term SFN administration was safe and did not induce any remarkably unfavorable growth of the CRAD rats. The Lewis rats with unilateral nephrectomies or transplanted kidneys in Groups $\mathrm{A}, \mathrm{C}$ and D shared almost identical ponderal growth trends. Most likely due to the strain differences, the F344 rats in Group B exhibited markedly slower weight gain compared with the rats in the other 3 groups.

Renal Function and Urinary Protein. As shown in Fig. 1(b-d), the SCr and BUN levels in Group C were all significantly higher than those in Groups A and B at 8, 12, 16, 20 and 24 weeks. From 8 to 24 weeks, the SCr and BUN levels of Groups A and B remained approximately stable, while a slow trend of increasing $\mathrm{SCr}$ and BUN levels was observed in Group C. Although no significant differences were found in the SCr and BUN levels between Groups $\mathrm{C}$ and $\mathrm{D}$ at any of the above time points, an overtly delayed increasing trend of the 2 indicators was observed in Group D. Compared with the stable 24 h-Pro levels in Groups A and B at 12, 16, 20 and 24 weeks, Group C exhibited a progressively increasing 24 h-Pro

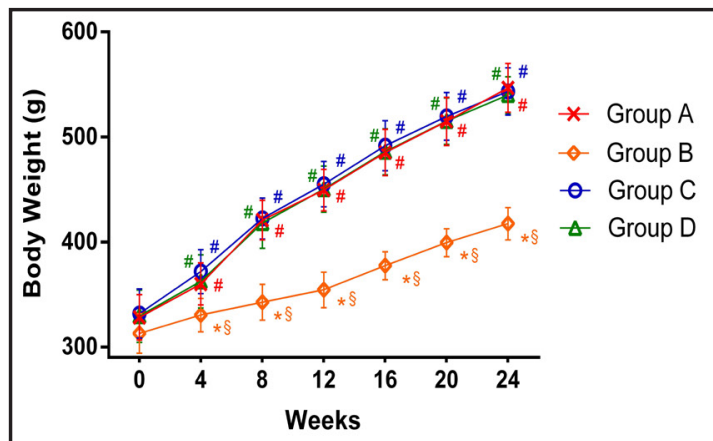

(a)

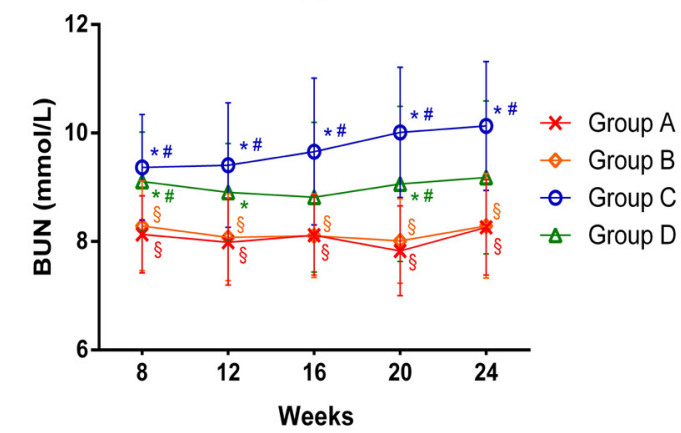

(c)

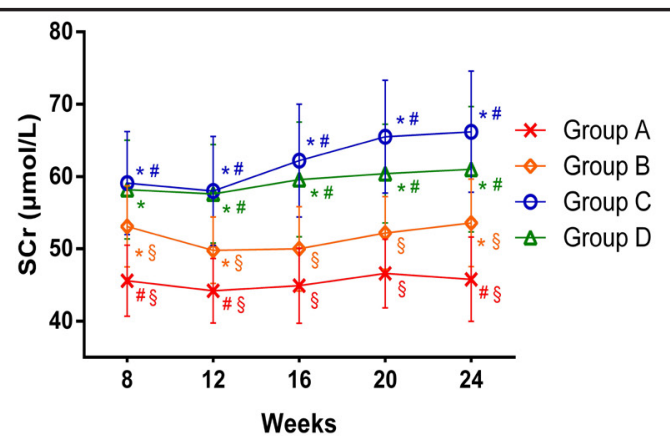

(b)

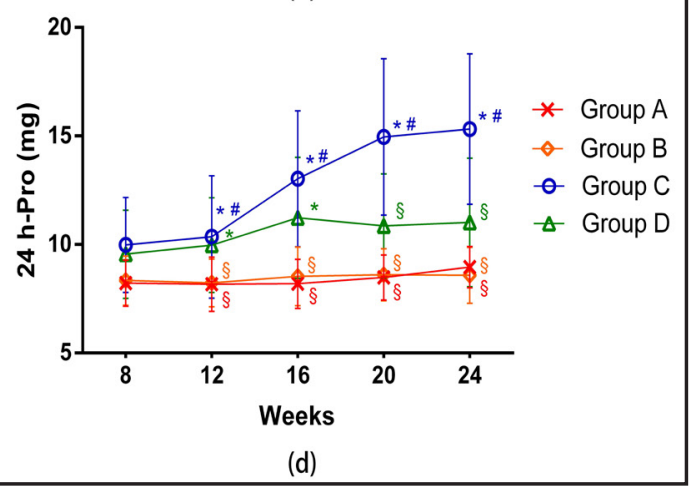

Fig. 1. Changes in body weight (a), serum creatinine ( $\mathrm{SCr}, \mathrm{b})$, blood urea nitrogen (BUN, c) and 24-hour urinary protein $(24 \mathrm{~h}-\mathrm{Pro}, \mathrm{d})$ during the observation period. Data are presented as the means \pm SDs of all rats in each group. *: versus Group A, $\mathrm{P}<0.05$; \#: versus Group B, $\mathrm{P}<0.05$; : versus Group C, $\mathrm{P}<0.05$. Group B exhibited significantly slower weight gain than Groups $\mathrm{A}, \mathrm{C}$ and $\mathrm{D}$, while the latter 3 groups shared similar increasing trends. Group C showed progressively increasing SCr, BUN and 24 h-Pro levels compared with Groups A and B. The SCr and BUN levels in Group C were significantly higher than those in Groups A and B at $8,12,16,20$ and 24 weeks. The $24 \mathrm{~h}$-Pro levels in Group C were significantly higher than those in Groups A and B at 12, 16, 20 and 24 weeks. Group D demonstrated delayed increases in SCr, BUN and $24 \mathrm{~h}$-Pro levels compared with Group C over the 24 weeks. The 24 h-Pro levels in Group D were significantly lower than those in Group C at 20 and 24 weeks. 


\section{Kidney \\ Blood Pressure Research}

Kidney Blood Press Res 2018;43:191-205

\begin{tabular}{|l|l|l|}
\hline DOI: 10.1159/000487501 & ( 2018 The Author(s). Published by S. Karger AG, Basel \\
\hline
\end{tabular}

Published online: February 21, 2018 www.karger.com/kbr

196

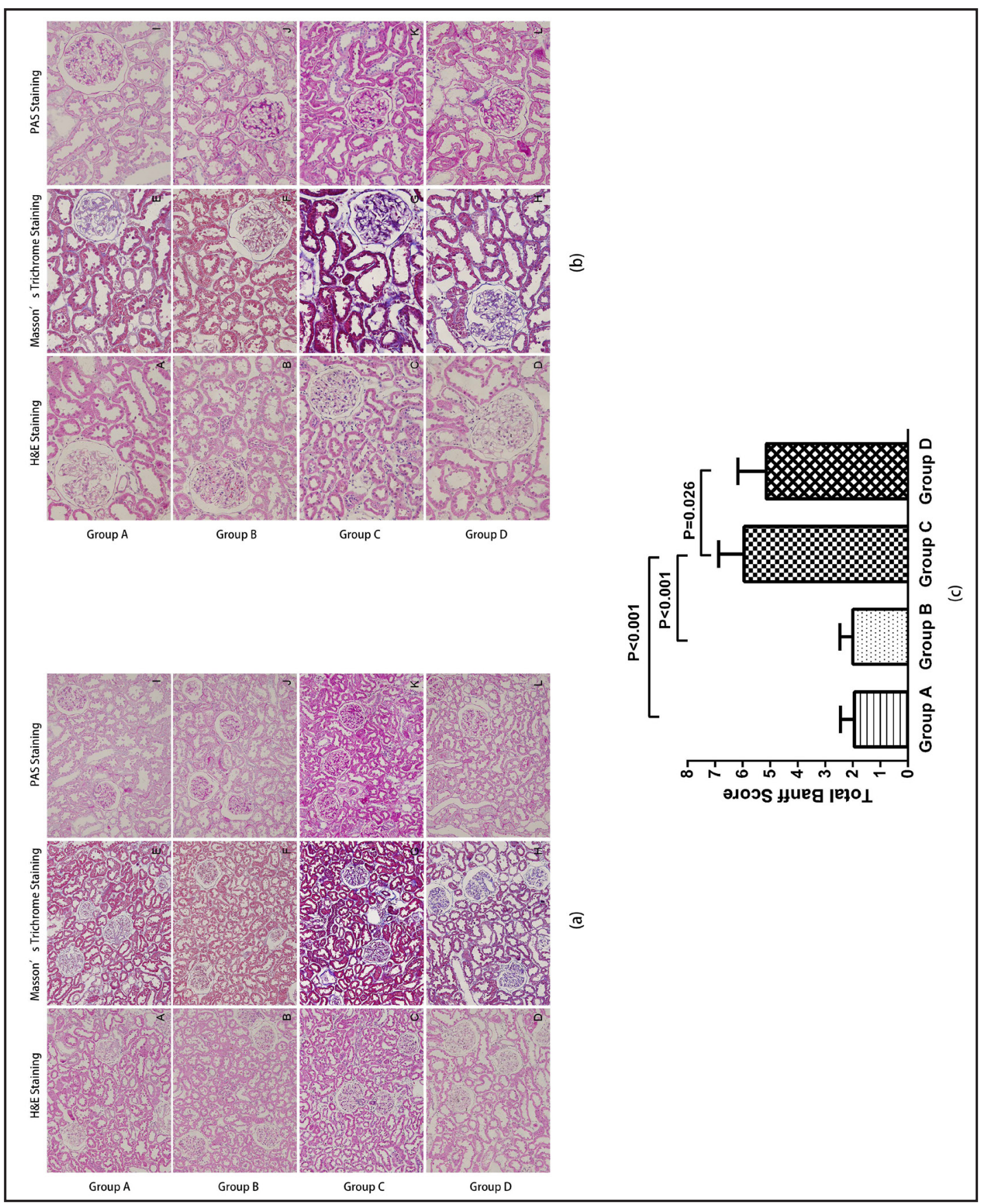

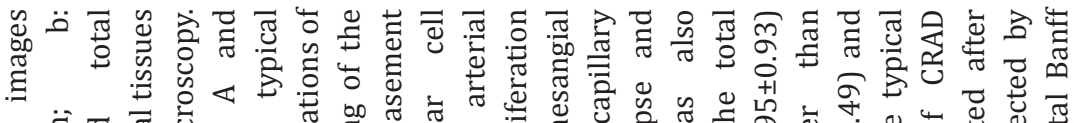

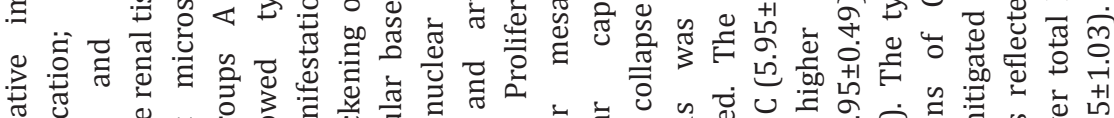

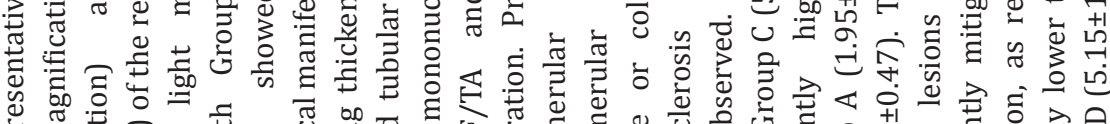

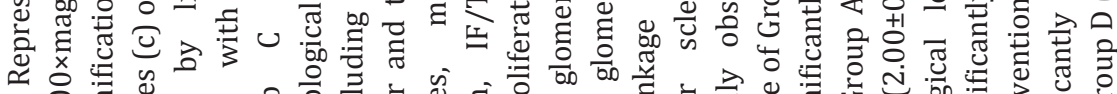

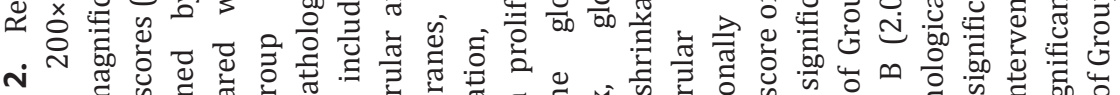

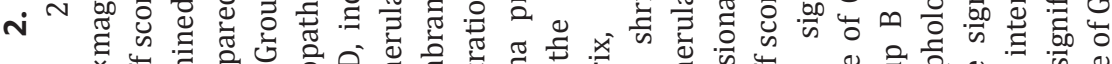

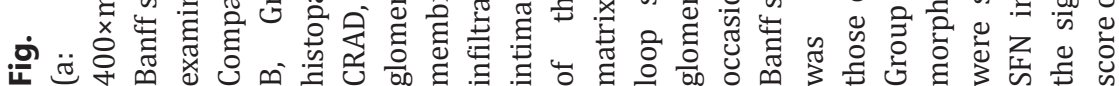




\section{Kidney Blood Pressure Research}

Lv et al.: The Association Between Oxidative Stress Alleviation and Chronic Renal

Allograft Dysfunction Improvement

level. Group D revealed an apparently delayed increase in $24 \mathrm{~h}$-Pro level relative to Group C; moreover, significantly lower 24 h-Pro levels were observed in Group D than those in Group $\mathrm{C}$ at 20 and 24 weeks. These functional measurements of the kidney demonstrated that SFN may retard renal allograft function deterioration and that such protective effects can be reflected earlier and more clearly by 24 h-Pro levels within 24 weeks after transplantation.

\section{Histopathological Changes}

As shown in Fig. 2(a-b), compared with Groups A and B, Group C demonstrated typical histopathological features of CRAD, including interstitial mononuclear cell infiltration, IF/ TA and tubular basement membrane thickening. The glomeruli revealed such lesions as mesangial matrix proliferation and glomerular basement membrane thickening. Glomerular capillary loop shrinkage or collapse was also occasionally observed. Intimal proliferation of renal arterioles was observed in some fields. The total Banff scores of Groups A, B, C and D were $1.95 \pm 0.49,2.00 \pm 0.47,5.95 \pm 0.93$ and $5.15 \pm 1.03$ respectively, as shown in Fig. 2(c). SFN attenuated the overall histopathological degree of CRAD in Group D; the protective effects were not specific to certain structures of the renal allografts but pertained more to general lesion alleviation.

\section{Oxidative Stress Assessment}

Oxidative Stress Indicators. As shown in Fig. 3(a-d), increased levels of MDA, 8-isoprostane, ox-LDL and 8-OHdG were observed in Group C compared with Groups A and $\mathrm{B}$, while concurrently decreased levels of the 4 indicators were observed in Group D compared with Group C. In the renal cortical tissues, the MDA levels in Groups A, B, C and D were $2.15 \pm 0.27 \mathrm{nmol} /$ mgprot, $2.09 \pm 0.30 \mathrm{nmol} /$ mgprot, $2.64 \pm 0.33 \mathrm{nmol} / \mathrm{mgprot}$ and $2.36 \pm 0.31 \mathrm{nmol} / \mathrm{mgprot}$; the 8-isoprostane levels in Groups A, B, C and D were 26.74 \pm 3.30 ng/gprot, $29.89 \pm 3.73 \mathrm{ng} /$ gprot, $41.29 \pm 5.34 \mathrm{ng} /$ gprot and 33.18 $\pm 4.54 \mathrm{ng} /$ gprot; the ox-LDL levels in Groups A, B, C and D were $2.86 \pm 0.36 \mu \mathrm{g} / \mathrm{mgprot}, 3.02 \pm 0.37 \mu \mathrm{g} / \mathrm{mgprot}, 4.65 \pm 0.63$

Fig. 3. Bar graphs depicting the levels of the oxidative indicators MDA (a), 8-isoprostane (b), ox-LDL (c) and 8-OHdG (d) in the renal cortical tissues. Data are shown as the means \pm SDs of all rats in each group. The MDA levels in Groups A, B, C and D were 2.15 \pm 0.27 $\mathrm{nmol} /$ mgprot, $\quad 2.09 \pm 0.30 \mathrm{nmol} /$ mgprot, $2.64 \pm 0.33 \mathrm{nmol} / \mathrm{mgprot}$ and $2.36 \pm 0.31 \mathrm{nmol} / \mathrm{mgprot}$; the 8-isoprostane levels in Groups A, B, $\mathrm{C}$ and D were $26.74 \pm 3.30 \mathrm{ng} /$ gprot, $29.89 \pm 3.73 \mathrm{ng} /$ gprot, $41.29 \pm 5.34$ ng/gprot and 33.18 \pm 4.54 ng/gprot; the ox-LDL levels in Groups A, B, C and D were $2.86 \pm 0.36 \mu \mathrm{g} / \mathrm{mgprot}$, $3.02 \pm 0.37 \mu \mathrm{g} / \mathrm{mgprot}, \quad 4.65 \pm 0.63$ $\mu \mathrm{g} / \mathrm{mgprot}$ and $3.34 \pm 0.46 \mu \mathrm{g} /$ mgprot; and the 8-OHdG levels in

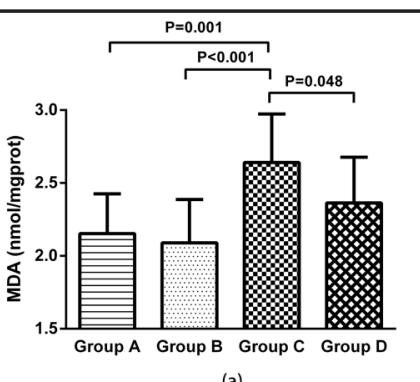

(a)

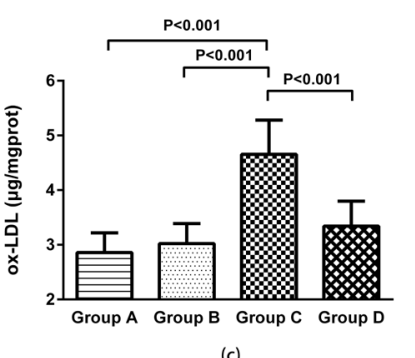

(c)

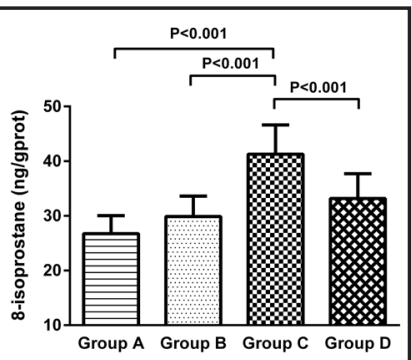

(b)

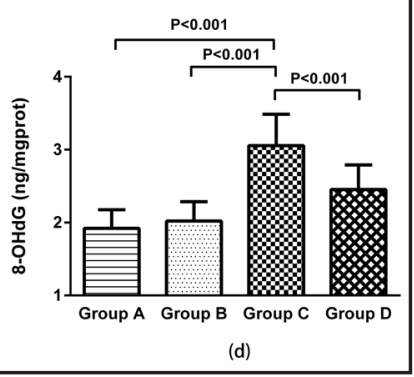
Groups A, B, C and D were 1.92 \pm 0.26 ng/mgprot, $2.02 \pm 0.27 \mathrm{ng} /$ mgprot, $3.06 \pm 0.43 \mathrm{ng} /$ mgprot and $2.45 \pm 0.34 \mathrm{ng} /$ mgprot. Oxidative stress was observed in CRAD, as reflected by the increased levels of MDA, 8-isoprostane, ox-LDL and 8-OHdG in Group C compared with Groups A and B. SFN alleviated the intrarenal oxidative stress, as demonstrated by the concurrently decreased levels of the 4 oxidative stress indicators in Group D compared with Group C. 


\section{Kidney \\ Blood Pressure \\ Research}

Kidney Blood Press Res 2018;43:191-205

\begin{tabular}{l|l}
\hline DOI: 10.1159/000487501 & (C) 2018 The Author(s). Published by S. Karger AG, Base
\end{tabular}

Published onlıne: February 21, 2018 www.karger.com/kbr

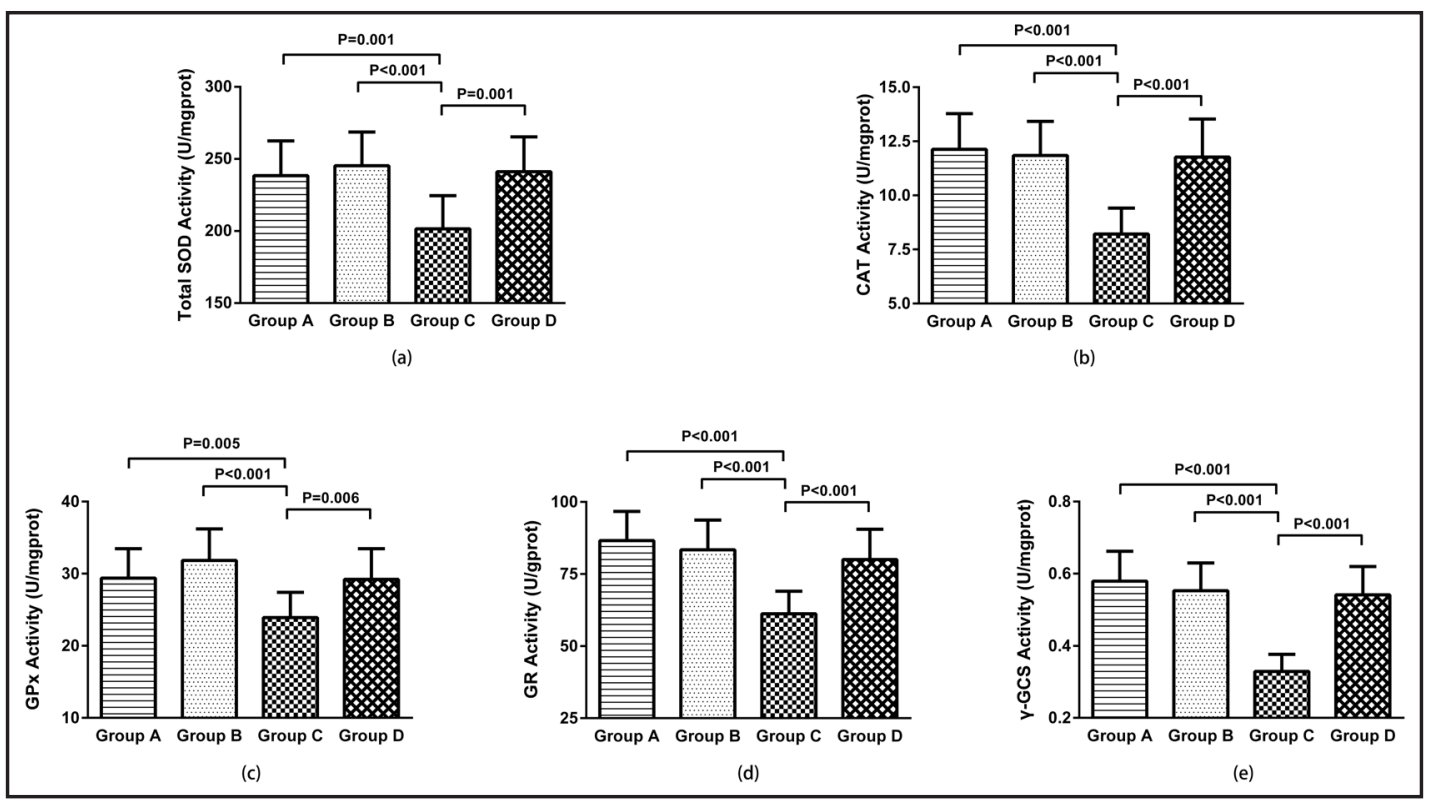

Fig. 4. Bar graphs depicting the activity levels of antioxidant enzymes the total SOD (a), CAT (b), GPx (c), GR (d) and $\gamma$-GCS (e) in the renal cortical tissues. Data are shown as the means \pm SDs of all rats in each group. The activity levels of total SOD in Groups A, B, C and D were 238.43 $\pm 24.19 \mathrm{U} / \mathrm{mgprot}, 245.27 \pm 23.38$ $\mathrm{U} /$ mgprot, 201.54 $\pm 23.04 \mathrm{U} / \mathrm{mgprot}$ and 241.23 $\pm 24.02 \mathrm{U} / \mathrm{mgprot}$; the activity levels of CAT in Groups A, $\mathrm{B}, \mathrm{C}$ and D were 12.13 $\pm 1.65 \mathrm{U} / \mathrm{mgprot}, 11.84 \pm 1.58 \mathrm{U} / \mathrm{mgprot}, 8.22 \pm 1.20 \mathrm{U} / \mathrm{mgprot}$ and $11.77 \pm 1.76 \mathrm{U} /$ mgprot; the activity levels of GPx in Groups A, B, C and D were 29.38 $\pm 4.08 \mathrm{U} / \mathrm{mgprot}, 31.85 \pm 4.36 \mathrm{U} / \mathrm{mgprot}$, $23.91 \pm 3.50 \mathrm{U} /$ mgprot and $29.22 \pm 4.24 \mathrm{U} /$ mgprot; the activity levels of GR in Groups A, B, C and D were 86.57 $\pm 10.16 \mathrm{U} /$ gprot, 83.39 $\pm 10.32 \mathrm{U} /$ gprot, $61.21 \pm 7.80 \mathrm{U} /$ gprot and 80.02 $\pm 10.50 \mathrm{U} /$ gprot; and the activity levels of $\gamma$-GCS in Groups A, B, C and D were 0.579 $\pm 0.083 \mathrm{U} /$ mgprot, $0.553 \pm 0.077 \mathrm{U} / \mathrm{mgprot}, 0.329 \pm 0.048$ $\mathrm{U} / \mathrm{mgprot}$ and $0.541 \pm 0.078 \mathrm{U} / \mathrm{mgprot}$. These results corresponded to the alterations in the oxidative stress indicators among the 4 groups, indicating inadequate intrarenal antioxidant forces in Group C compared with Groups A and B and demonstrating the effect of continuous SFN intervention on sustaining the activity levels of the 5 antioxidant enzymes in Group D compared with Group C.

$\mu \mathrm{g} / \mathrm{mgprot}$ and 3.34 $\pm 0.46 \mu \mathrm{g} / \mathrm{mgprot}$; and the 8-OHdG levels in Groups A, B, C and D were $1.92 \pm 0.26 \mathrm{ng} / \mathrm{mgprot}, 2.02 \pm 0.27 \mathrm{ng} /$ mgprot, $3.06 \pm 0.43 \mathrm{ng} / \mathrm{mgprot}$ and $2.45 \pm 0.34 \mathrm{ng} /$ mgprot. These results showed the increased intrarenal oxidative stress in the allografts of rats with CRAD and that such conditions can be alleviated successfully by continuous SFN intervention.

Antioxidant Enzymes. Contrary to the alterations in the oxidative stress indicators among the 4 groups, as shown in Fig. 4(a-e), decreased activity levels of the antioxidant enzymes total SOD, CAT, GPx, GR and $\gamma$-GCS were found in Group C compared with Groups $\mathrm{A}$ and $\mathrm{B}$, while the activity levels of the 5 enzymes were preserved in Group D. In the renal cortical tissues, the activity levels of total SOD in Groups A, B, C and D were $238.43 \pm 24.19$ $\mathrm{U} /$ mgprot, 245.27 $\pm 23.38 \mathrm{U} /$ mgprot, 201.54 $\pm 23.04 \mathrm{U} /$ mgprot and 241.23 $\pm 24.02 \mathrm{U} / \mathrm{mgprot}$; the activity levels of CAT in Groups A, B, C and D were 12.13 $\pm 1.65 \mathrm{U} /$ mgprot, $11.84 \pm 1.58 \mathrm{U} /$ mgprot, 8.22 $\pm 1.20 \mathrm{U} / \mathrm{mgprot}$ and $11.77 \pm 1.76 \mathrm{U} / \mathrm{mgprot}$; the activity levels of GPx in Groups $\mathrm{A}, \mathrm{B}, \mathrm{C}$ and D were 29.38 $\pm 4.08 \mathrm{U} / \mathrm{mgprot}, 31.85 \pm 4.36 \mathrm{U} / \mathrm{mgprot}, 23.91 \pm 3.50 \mathrm{U} / \mathrm{mgprot}$ and $29.22 \pm 4.24 \mathrm{U} /$ mgprot; the activity levels of GR in Groups A, B, C and D were $86.57 \pm 10.16$ $\mathrm{U} /$ gprot, 83.39 $\pm 10.32 \mathrm{U} /$ gprot, 61.21 $\pm 7.80 \mathrm{U} /$ gprot and $80.02 \pm 10.50 \mathrm{U} /$ gprot; and the activity levels of $\gamma$-GCS in Groups A, B, C and D were $0.579 \pm 0.083 \mathrm{U} / \mathrm{mgprot}, 0.553 \pm 0.077$ $\mathrm{U} / \mathrm{mgprot}, 0.329 \pm 0.048 \mathrm{U} / \mathrm{mgprot}$ and $0.541 \pm 0.078 \mathrm{U} / \mathrm{mgprot}$. These results demonstrated 


\section{Kidney Blood Pressure Research}

the inadequate antioxidant forces in the CRAD renal allografts and the effect of SFN on sustaining the activity levels of these intrarenal antioxidant enzymes.

\section{Immunohistochemistry}

To explore changes in the Nrf2-HO-1/NQO-1 signaling pathway, the renal expression levels of Nrf2, HO-1 and NQO-1 were investigated by immunohistochemistry. As shown in Fig. 5(a-b), Nrf2 was widely expressed in the cytoplasm of intrinsic glomerular cells in Groups A and B, especially in tubular epithelial cells. Nrf2 nuclear translocation was also observed in some glomerular and tubular cells. This situation was in accordance with the fact that Nrf2 is ubiquitously expressed in different cell types and can be activated by oxidative stress or other stimuli generated under physiological conditions, followed by nuclear translocation [15]. In comparison, in Group C, Nrf2 expression levels were sharply reduced in the cytoplasm and nuclei of the renal allograft cells. Analogously, the expression levels of the downstream proteins HO-1 and NQO-1 in the cytoplasm were both lower in Group C than those in Groups A and B. The downregulation of Nrf2, HO-1 and NQO-1 expression levels was represented by lower IOD/Area values in Group C than those in Groups A and B, as shown in Fig. 5(c-e). In Group D, SFN administration prominently improved the cytoplasmic and

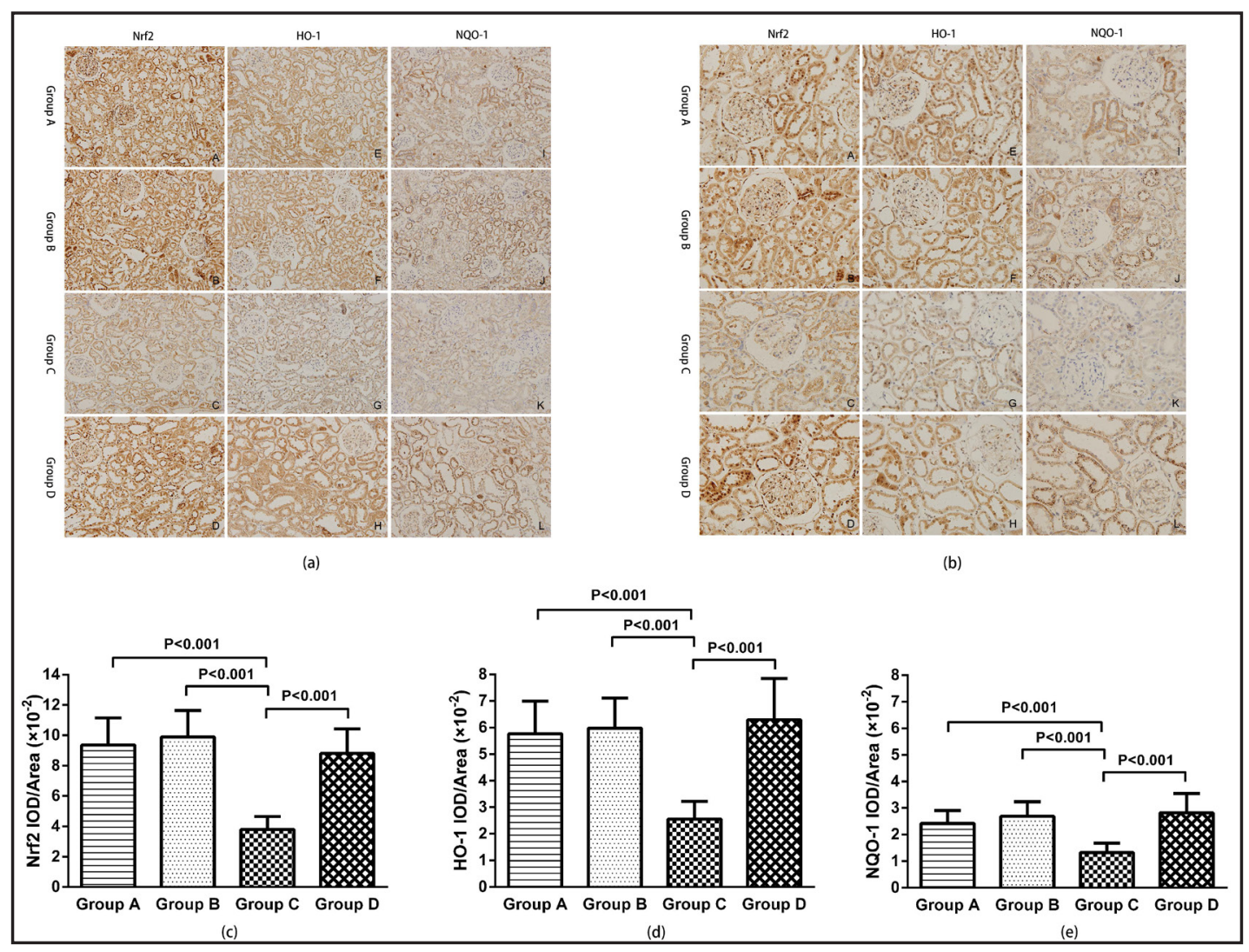

Fig. 5. Immunohistochemical (a: 200×magnification; b: 400×magnification) and semi-quantitative analyses (c - e) represented by IOD/Area values for Nrf2, HO-1 and NQO-1 expression levels. The nuclear and cytoplasmic Nrf2 expression levels in glomeruli and tubules were significantly lower in Group $C$ than those in Groups A and B. The cytoplasmic HO-1 and NQO-1 expression levels in glomeruli and tubules were also decreased. Increased Nrf2, HO-1 and NQO-1 expression levels were observed in the renal allografts of Group D. The IOD/Area values for Nrf2, HO-1 and NQO-1 in Group C were $(3.79 \pm 0.86) \times 10^{-2},(2.56 \pm 0.67) \times 10^{-2}$ and $(1.32 \pm 0.36) \times 10^{-2}$, respectively, which were all significantly lower than those in Group A $\left[(9.36 \pm 1.78) \times 10^{-}\right.$ 2 , $(5.77 \pm 1.23) \times 10^{-2}$ and $\left.(2.42 \pm 0.49) \times 10^{-2}\right]$ and Group B $\left[(9.88 \pm 1.75) \times 10^{-2},(5.98 \pm 1.13) \times 10^{-2}\right.$ and $\left.(2.69 \pm 0.55) \times 10^{-2}\right]$. Group D showed significantly increased IOD/Area values for Nrf2 $\left[(8.80 \pm 1.63) \times 10^{-2}\right]$, HO-1 $\left[(6.30 \pm 1.55) \times 10^{-2}\right]$ and NQO-1 $\left[(2.82 \pm 0.73) \times 10^{-2}\right]$ compared with Group C. 


\section{Kidney \\ Blood Pressure \\ Research}

Fig. 6. Representative Western blots (a-d) and IOD values of the target bands relative to the internal control bands depicting the expression levels (eh) of total Nrf2, HO-1, NQO-1 and nuclear Nrf2. Compared with Group C, Group D showed significantly increased levels of total Nrf2, HO-1, NQO-1 and nuclear Nrf2 expression. Group C exhibited the lowest levels of total Nrf2, HO-1, NQO1 and nuclear Nrf2 expression among the 4 groups.

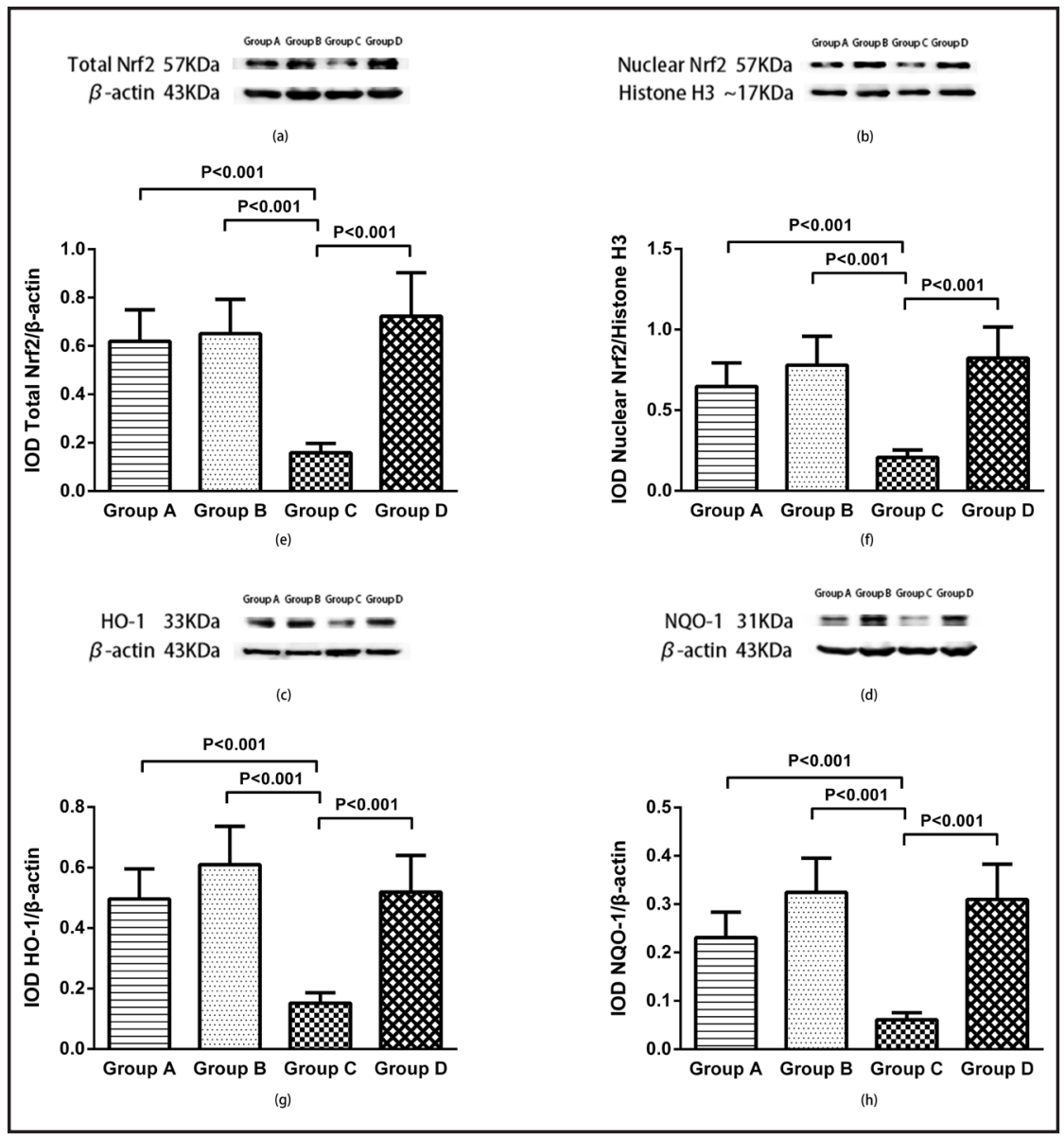

nuclear expression levels of Nrf2 in the renal allograft cells, leading to increased HO-1 and NQO-1 expression levels, as demonstrated by the similarly increased IOD/Area values. These observations suggested that an in situ deficiency of Nrf2 signaling pathway may occur during CRAD. Furthermore, the continuous SFN intervention after the renal transplantation may help preserve normal function of intrarenal Nrf2-HO-1/NQO-1 signaling pathway.

\section{Western Blot Analysis}

Total renal Nrf2, HO-1, NQO-1 and nuclear Nrf2 expression levels were compared among the groups through Western blot analyses to further validate changes in Nrf2 signaling pathway. As shown in Fig. 6(a-h), compared with Groups A and B, Group C showed significantly decreased levels of total Nrf2, HO-1, NQO-1 and nuclear Nrf2 expression in the renal allografts. Moreover, compared with Group C, Group D demonstrated elevated levels of total Nrf2, HO-1, NQO-1 and nuclear Nrf2 expression. These variations in Nrf2-HO-1/NQO-1 signaling pathway were consistent with the immunohistochemical results.

\section{Discussion}

Based on the F344-to-Lewis rat CRAD model, the results of this study suggest that there is a relationship between oxidative stress alleviation via activating the Nrf2-HO-1/NQO-1 signaling pathway with continuous SFN intervention beginning at the time of transplantation and functional improvement. In addition, delayed histopathological deterioration was observed in the renal allografts. Similar to our findings, accumulating evidence has 


\section{Kidney Blood Pressure Research}

Kidney Blood Press Res 2018;43:191-205

\begin{tabular}{l|l}
\hline DOI: 10.1159/000487501 & (c) 2018 The Author(s). Published by S. Karger AG, Basel
\end{tabular}

Published onlıne: February 21, 2018

www.karger.com/kb

201

Lv et al.: The Association Between Oxidative Stress Alleviation and Chronic Rena

Allograft Dysfunction Improvement

demonstrated that Nrf2 activation can play a pivotal role in protecting the kidney against a variety of disorders. For instance, in a rat model of renal ischemia-reperfusion injury, preactivation of Nrf2 and the downstream protective proteins HO-1, NQO-1, GR and GPx by SFN effectively reduced renal dysfunction and injury [16]. Continuous SFN intervention for 3 months also prevented the diabetic induction of renal dysfunction, fibrosis, inflammation and oxidative damage by activating the Nrf2 and its downstream antioxidant proteins in a type 1 diabetic mouse model [17]. In addition, it was validated in a rat model that SFN-induced activation of the Nrf2 signaling pathway ameliorated unilateral ureteral obstruction-induced renal damage and alleviated renal dysfunction and pathological changes caused by contrastinduced nephropathy [18, 19]. Furthermore, animals with deficient or dysfunctional Nrf2 signaling pathway are more susceptible to various kidney diseases, including acute kidney injury, lupus-like autoimmune nephritis, hyperglycemia-induced renal injury and progressive focal glomerulosclerosis [20-23]. The key underlying mechanism for the abovementioned favorable effects on the kidney after Nrf2 signaling pathway activation is, at least in part, the alleviation of oxidative stress. Oxidative stress-induced cell and tissue damages can be attributed to an excess of reactive oxygen species (ROS) and inadequate antioxidant defenses. ROS can oxidize bioactive molecules, including proteins, lipids, nucleic acids and carbohydrates, leading to altered functions, activities and intracellular interactions, thus interfering with normal cell and tissue functions [24]. An increased prevalence of oxidative stress has already been observed in chronic kidney disease (CKD) and dialysis patients [25]. Furthermore, new investigations on the association between oxidative stress and CRAD have recently emerged, perhaps inspired by the common chronic and progressive clinical courses of CKD and CRAD. Another study that used the same CRAD model as in this study also reported increased levels of oxidative stress indicators, including superoxide anion, inducible nitric oxide synthase and endothelial nitric oxide synthase in renal allografts; in addition, that study reported evidence related to the tubular epithelialto-mesenchymal transition (EMT), suggesting that an IF/TA-associated EMT may occur concurrently with oxidative stress in CRAD [26]. Oxidative stress profiles can already be established in CRAD patients using serum and urine biomarkers; additionally, an association has been established between the increased oxidative stress burden observed in these patients and impaired intrarenal oxygenation [27]. In this study, evidence of oxidative stress was observed through increased levels of the classical indicators MDA, 8-isoprostane, oxLDL and 8-OHdG in the CRAD renal allografts. MDA, which is an end-product derived from the breakdown of polyunsaturated fatty acids and related esters, provides a convenient index of lipid peroxidation [28]. 8-isoprostane is also a reliable and specific in vivo marker of oxidative stress produced by free radical peroxidation of arachidonic acid [29], while oxLDL can further reflect early lipid peroxidation [30]. 8-OHdG is a biomarker of oxidative damage to DNA and is, therefore, another well-accepted index of oxidative stress [31-32]. The concurrently increased levels of these indicators validated the increased intrarenal oxidative stress in CRAD. Meanwhile, the inadequate antioxidant defenses were portrayed by decreased activity levels of the antioxidant enzymes total SOD, CAT, GPx, GR and $\gamma$-GCS. SOD can catalyze the dismutation of the superoxide radical into oxygen or hydrogen peroxide, which is further degraded into water and oxygen by CAT, leading to final ROS elimination [33]. GPx and GR are biomarkers linking ROS detoxification with the metabolism of glutathione, which represents the majority of the thiol antioxidants and redox buffers of the cell [3435]. GPx converts peroxides and hydroxyl radicals into nontoxic forms in conjunction with the oxidation of reduced glutathione into the oxidized form, glutathione disulfide; the latter is then converted back to reduced glutathione by GR [36]. $\gamma$-GCS, which controls the ratelimiting step of glutathione synthesis, is also an important antioxidant enzyme [37-38]. The decreased activity levels of these protective enzymes, culminating in inadequate antioxidant forces, manifested as the pro-oxidative status observed in CRAD. Considering the typical histopathological manifestations of CRAD, it is reasonable to postulate that oxidative stress could be one reason for the unexplained IF/TA in CRAD. This idea is further supported by the 


\section{Kidney Blood Pressure Research}

Kidney Blood Press Res 2018;43:191-205

\begin{tabular}{l|l}
\hline DOI: 10.1159/000487501 & (c) 2018 The Author(s). Published by S. Karger AG, Basel
\end{tabular}

Published onlıne: February 21, 2018

www.karger.com/kb

Lv et al.: The Association Between Oxidative Stress Alleviation and Chronic Rena

Allograft Dysfunction Improvement

relevant alleviation of histopathological changes in the SFN-treated CRAD group. HO-1 and NQO-1 are two representative Nrf2 downstream proteins that were selected and described in detail in this study to illustrate the renal antioxidant capacity after SFN treatment. As common competitors against oxidative and inflammatory stresses in cells and tissues, HO-1 can result in degradation of heme moieties, generating bilirubin, which is an antioxidant capable of scavenging peroxy radicals and inhibiting lipid peroxidation [39]. NQO-1 can maintain coenzyme $\mathrm{Q}$ (ubiquinone) in the antioxidant form (ubiquinol) in cellular membranes, inhibiting membrane lipid peroxidation. Furthermore, ubiquinols can react directly with oxygen radicals, preventing oxidative stress damage to diverse biomolecules [40]. This study showed that functions of intrarenal antioxidative mechanisms, represented by HO-1 and NQO-1, along with the activity levels of total SOD, CAT, GPx, GR and $\gamma$-GCS, may recover partially after SFN treatment. Because total SOD, CAT, GPx, GR and $\gamma$-GCS are also influenced by the Nrf2 signaling pathway [13], we could not differentiate whether the restoration of their activities was a direct effect of SFN, a spontaneous occurrence due to relief of the oxidative stress milieu caused by SFN, or both. Importantly, we could conclude that a cellular redox shift toward a more antioxidant state rather than a pro-oxidant milieu was promoted by SFN: the gap between excess ROS and inadequate antioxidants was narrowed, as reflected by the concurrently decreased levels of MDA, 8-isoprostane, ox-LDL and 8-OHdG in the SFN intervention group. From the long-term observation of renal function over 24 weeks, the protective effects of SFN on proteinuria seemed more pronounced than the effects on SCr and BUN levels. Furthermore, the protective effects of SFN were gradual and not apparent within a short time-span after transplantation. Long-term and continuous SFN administration is likely needed to sustain the intrarenal antioxidant environment and postpone CRAD progression. However, considering the histopathology-associated total Banff scores, renal function and $24 \mathrm{~h}$-Pro in the SFN intervention group, the current dose of post-transplantation SFN was insufficient to completely prevent CRAD. However, it remains uncertain whether larger SFN doses or more powerful Nrf2 activators would confer stronger protective effects on renal allografts. The exact duration of the protective effects of SFN on CRAD is also unclear. More studies are needed to clarify these issues in the future.

Despite oxidative stress and other potential stimuli that should have induced Nrf2 activation in the CRAD group in this study, we discovered a "paradoxical" reduction in the cytoplasmic and nuclear Nrf2 along with cytoplasmic HO-1 and NQO-1 expression levels, similar to the decreased levels of the antioxidant enzymes activity, signifying an inadequate reserve and/or disordered Nrf2-HO-1/NQO-1 signaling pathway activation in the renal allografts. Similar phenomena have been reproduced in a rat model of chronic renal failure and spontaneous focal glomerulosclerosis [23, 41]. Consistent with our study, both models exhibited conspicuous intrarenal oxidative stress. Thus, we surmised that the maladaptive response of the Nrf2 signaling pathway, namely, the decompensation and/or dysfunction of the antioxidant defense system, occurred in the overwhelming milieu of oxidative stress in the renal allografts. As such, we believed that there was probably a period of time when the intrarenal Nrf2 signaling pathway was upregulated in response to oxidative stress during early-stage CRAD. From the recuperative cytoplasmic and nuclear Nrf2 expression levels in the SFN intervention group, we concluded that the reduced oxidative stress burden caused by exogenous antioxidants could help preserve and maintain normal endogenous antioxidant defense function. Of course, cells and tissues should not always "surrender" when facing oxidative stress; responses might depend on the degree and/or duration of oxidative stress per se and/or characteristics of the defense system itself. Currently, the detailed mechanisms of disorders of the intrarenal Nrf2 signaling pathway in the context of oxidative stress in CRAD remain unknown and require further investigation.

The limitations of this study are as follows. First, the positive effects of SFN via activating the Nrf2-HO-1/NQO-1 signaling pathway on CRAD could have been further clarified if SFNtreated Nrf2-knockout or Nrf2-inhibited rat recipients were examined [42]. Second, the mechanisms of the protective effects of SFN on kidney may be versatile, for instance, SFN 


\section{Kidney \\ Blood Pressure Research}

\begin{tabular}{l}
\hline Kidney Blood Press Res 2018;43:191-205 \\
\hline \begin{tabular}{l|l} 
DOI: 10.1159/000487501 & $\begin{array}{l}\text { @ } 2018 \text { The Author(s). Published by S. Karger AG, Basel } \\
\text { www.karger.com/kbr }\end{array}$ \\
Publisned onlIne: rebruary 21, 2018
\end{tabular}
\end{tabular}

Lv et al.: The Association Between Oxidative Stress Alleviation and Chronic Renal

Allograft Dysfunction Improvement

can also play an anti-inflammatory role by inhibiting the NF- $\kappa B$ signaling pathway [43]. Consequently, the observed improvements of renal allografts treated with SFN may not be solely attributable to the alleviation of oxidative stress. This study was insufficient to fully elucidate other possible "confounding" mechanisms of the protective effects of SFN on renal allografts. Despite these limitations, to the best of our knowledge, this study demonstrates for the first time the association between oxidative stress alleviation via activating the Nrf2HO-1/NQO-1 signaling pathway continuously by SFN and CRAD alleviation in the F344-toLewis rat renal transplantation model. These findings provide in vivo experimental evidence that natural compounds such as SFN may be used therapeutically to relieve progressive damage to renal allografts in CRAD.

\section{Conclusion}

The current study illustrates an association between oxidative stress alleviation via continuous SFN-induced Nrf2-HO-1/NQO-1 signaling pathway activation and renal functional and morphological improvements in a rat model of CRAD. As such, the antioxidant SFN may be a promising therapy for delaying the progression of CRAD.

\section{Disclosure Statement}

The authors have no conflicts of interest to disclose.

\section{Acknowledgements}

This study was supported by the National Natural Science Foundation of China (81270840).

\section{References}

1 Wang JH, Skeans MA, Israni AK: Current status of kidney transplant outcomes: Dying to survive. Adv Chronic Kidney Dis 2016;23:281-286.

2 Shi B, Yuan M: The guideline for immunosuppressive therapy for renal transplant recipients in China (Version 2016). Organ Transplantation 2016:327-331.

-3 Cecka JM: The UNOS renal transplant registry. Clin Transpl 2002:1-20.

4 Starzl TE, Klintmalm GB, Weil RR, Porter KA, Iwatsuki S, Schroter GP, Fernandez-Bueno C, MacHugh $\mathrm{N}$ : Cyclosporin A and steroid therapy in sixty-six cadaver kidney recipients. Surg Gynecol Obstet 1981;153:486-494.

5 Waller JR, Nicholson ML: Molecular mechanisms of renal allograft fibrosis. Br J Surg 2001;88:1429-1441.

-6 Fadili W, Habib AM, Laouad I: Chronic renal allograft dysfunction: Risk factors, immunology and prevention. Arab J Nephrol Transplant 2013;6:45-50.

7 Solez K, Colvin RB, Racusen LC, Sis B, Halloran PF, Birk PE, Campbell PM, Cascalho M, Collins AB, Demetris AJ, Drachenberg CB, Gibson IW, Grimm PC, Haas M, Lerut E, Liapis H, Mannon RB, Marcus PB, Mengel M, Mihatsch MJ, et al.: Differential diagnosis of chronic allograft injury and elimination of chronic allograft nephropathy ('CAN'). Am J Transplant 2007;7:518-526.

8 Safinia N, Afzali B, Atalar K, Lombardi G, Lechler RI: T-cell alloimmunity and chronic allograft dysfunction. Kidney Int Suppl 2010:S2-S12.

-9 Stegall MD, Park WD, Larson TS, Gloor JM, Cornell LD, Sethi S, Dean PG, Prieto M, Amer H, Textor S, Schwab T, Cosio FG: The histology of solitary renal allografts at 1 and 5 years after transplantation. Am J Transplant 2011;11:698-707. 


\section{Kidney \\ Blood Pressure Research}

10 O'Connell PJ, Zhang W, Menon MC, Yi Z, Schroppel B, Gallon L, Luan Y, Rosales IA, Ge Y, Losic B, Xi C, Woytovich C, Keung KL, Wei C, Greene I, Overbey J, Bagiella E, Najafian N, Samaniego M, Djamali A, et al.: Biopsy transcriptome expression profiling to identify kidney transplants at risk of chronic injury: A multicentre, prospective study. Lancet 2016;388:983-993.

11 Gourishankar S, Leduc R, Connett J, Cecka JM, Cosio F, Fieberg A, Gaston R, Halloran P, Hunsicker L, Kasiske B, Rush D, Grande J, Mannon R, Matas A: Pathological and clinical characterization of the 'troubled transplant': Data from the DeKAF study. Am J Transplant 2010;10:324-330.

-12 Ruiz S, Pergola PE, Zager RA, Vaziri ND: Targeting the transcription factor Nrf2 to ameliorate oxidative stress and inflammation in chronic kidney disease. Kidney Int 2013;83:1029-1041.

$\checkmark 13$ Choi BH, Kang KS, Kwak MK: Effect of redox modulating NRF2 activators on chronic kidney disease. Molecules 2014;19:12727-12759.

14 Racusen LC, Solez K, Colvin RB, Bonsib SM, Castro MC, Cavallo T, Croker BP, Demetris AJ, Drachenberg CB, Fogo AB, Furness P, Gaber LW, Gibson IW, Glotz D, Goldberg JC, Grande J, Halloran PF, Hansen HE, Hartley B, Hayry PJ, et al.: The Banff 97 working classification of renal allograft pathology. Kidney Int 1999;55:713723.

15 Zoja C, Benigni A, Remuzzi G: The Nrf2 pathway in the progression of renal disease. Nephrol Dial Transplant 2014;29:i19-i24.

16 Yoon HY, Kang NI, Lee HK, Jang KY, Park JW, Park BH: Sulforaphane protects kidneys against ischemiareperfusion injury through induction of the Nrf2-dependent phase 2 enzyme. Biochem Pharmacol 2008;75:2214-2223.

17 Cui W, Bai Y, Miao X, Luo P, Chen Q, Tan Y, Rane MJ, Miao L, Cai L: Prevention of diabetic nephropathy by sulforaphane: Possible role of Nrf2 upregulation and activation. Oxid Med Cell Longev 2012;2012:821936.

18 Chung SD, Lai TY, Chien CT, Yu HJ: Activating Nrf-2 signaling depresses unilateral ureteral obstructionevoked mitochondrial stress-related autophagy, apoptosis and pyroptosis in kidney. PLoS One 2012;7:e47299.

19 Zhao Z, Liao G, Zhou Q, Lv D, Holthfer H, Zou H: Sulforaphane Attenuates Contrast-Induced Nephropathy in Rats via Nrf2/HO-1 Pathway. Oxid Med Cell Longev 2016;2016:9825623.

20 Liu M, Grigoryev DN, Crow MT, Haas M, Yamamoto M, Reddy SP, Rabb H: Transcription factor Nrf2 is protective during ischemic and nephrotoxic acute kidney injury in mice. Kidney Int 2009;76:277-285.

21 Yoh K, Itoh K, Enomoto A, Hirayama A, Yamaguchi N, Kobayashi M, Morito N, Koyama A, Yamamoto M, Takahashi S: Nrf2-deficient female mice develop lupus-like autoimmune nephritis. Kidney Int 2001;60:1343-1353.

-22 Yoh K, Hirayama A, Ishizaki K, Yamada A, Takeuchi M, Yamagishi S, Morito N, Nakano T, Ojima M, Shimohata H, Itoh K, Takahashi S, Yamamoto M: Hyperglycemia induces oxidative and nitrosative stress and increases renal functional impairment in Nrf2-deficient mice. Genes Cells 2008;13:1159-1170.

-23 Kim HJ, Sato T, Rodriguez-Iturbe B, Vaziri ND: Role of intrarenal angiotensin system activation, oxidative stress, inflammation, and impaired nuclear factor-erythroid-2-related factor 2 activity in the progression of focal glomerulosclerosis. J Pharmacol Exp Ther 2011;337:583-590.

-24 Stanton RC: Oxidative stress and diabetic kidney disease. Curr Diab Rep 2011;11:330-336.

-25 Saito H: Toxico-pharmacological perspective of the Nrf2-Keap1 defense system against oxidative stress in kidney diseases. Biochem Pharmacol 2013;85:865-872.

26 Djamali A, Reese S, Yracheta J, Oberley T, Hullett D, Becker B: Epithelial-to-mesenchymal transition and oxidative stress in chronic allograft nephropathy. Am J Transplant 2005;5:500-509.

-27 Djamali A, Sadowski EA, Muehrer RJ, Reese S, Smavatkul C, Vidyasagar A, Fain SB, Lipscomb RC, Hullett DH, Samaniego-Picota M, Grist TM, Becker BN: BOLD-MRI assessment of intrarenal oxygenation and oxidative stress in patients with chronic kidney allograft dysfunction. Am J Physiol Renal Physiol 2007;292:F513-F522.

28 Wong SH, Knight JA, Hopfer SM, Zaharia O, Leach CJ, Sunderman FJ: Lipoperoxides in plasma as measured by liquid-chromatographic separation of malondialdehyde-thiobarbituric acid adduct. Clin Chem 1987;33:214-220.

29 Roberts LJ, Morrow JD: Measurement of F(2)-isoprostanes as an index of oxidative stress in vivo. Free Radic Biol Med 2000;28:505-513. 


\section{Kidney \\ Blood Pressure Research}

Kidney Blood Press Res 2018;43:191-205

\begin{tabular}{l|l}
\hline DOI: 10.1159/000487501 & (C) 2018 The Author(s). Published by S. Karger AG, Base
\end{tabular}

Published onlıne: February 21, 2018 www.karger.com/kbr

Lv et al.: The Association Between Oxidative Stress Alleviation and Chronic Renal

Allograft Dysfunction Improvement

-30 Yurdakan G, Tekin IO, Comert M, Acikgoz S, Sipahi EY: The presence of oxidized low-density lipoprotein and inducible nitric oxide synthase expression in renal damage after intestinal ischemia reperfusion. Kaohsiung J Med Sci 2012;28:16-22.

31 Valko M, Rhodes CJ, Moncol J, Izakovic M, Mazur M: Free radicals, metals and antioxidants in oxidative stress-induced cancer. Chem Biol Interact 2006;160:1-40.

-32 Liu CM, Ma JQ, Sun YZ: Quercetin protects the rat kidney against oxidative stress-mediated DNA damage and apoptosis induced by lead. Environ Toxicol Pharmacol 2010;30:264-271.

-33 Matsubara K, Higaki T, Matsubara Y, Nawa A: Nitric oxide and reactive oxygen species in the pathogenesis of preeclampsia. Int J Mol Sci 2015;16:4600-4614.

34 Paskerova H, Hilscherova K, Blaha L: Oxidative stress and detoxification biomarker responses in aquatic freshwater vertebrates exposed to microcystins and cyanobacterial biomass. Environ Sci Pollut Res Int 2012;19:2024-2037.

-35 Hanschmann EM, Godoy JR, Berndt C, Hudemann C, Lillig CH: Thioredoxins, glutaredoxins, and peroxiredoxins--molecular mechanisms and health significance: From cofactors to antioxidants to redox signaling. Antioxid Redox Signal 2013;19:1539-1605.

-36 Wu JQ, Kosten TR, Zhang XY: Free radicals, antioxidant defense systems, and schizophrenia. Prog Neuropsychopharmacol Biol Psychiatry 2013;46:200-206.

-37 Wild AC, Mulcahy RT: Regulation of gamma-glutamylcysteine synthetase subunit gene expression: Insights into transcriptional control of antioxidant defenses. Free Radic Res 2000;32:281-301.

-38 Zhou P, Yu JF, Zhao CG, Sui FX, Teng X, Wu YB: Therapeutic potential of EGCG on acute renal damage in a rat model of obstructive nephropathy. Mol Med Rep 2013;7:1096-1102.

-39 Sikorski EM, Hock T, Hill-Kapturczak N, Agarwal A: The story so far: Molecular regulation of the heme oxygenase-1 gene in renal injury. Am J Physiol Renal Physiol 2004;286:F425-F441.

-40 Chen XL, Varner SE, Rao AS, Grey JY, Thomas S, Cook CK, Wasserman MA, Medford RM, Jaiswal AK, Kunsch C: Laminar flow induction of antioxidant response element-mediated genes in endothelial cells. A novel anti-inflammatory mechanism. J Biol Chem 2003;278:703-711.

41 Kim HJ, Vaziri ND: Contribution of impaired Nrf2-Keap1 pathway to oxidative stress and inflammation in chronic renal failure. Am J Physiol Renal Physiol 2010;298:F662-F671.

-42 Wu W, Qiu Q, Wang H, Whitman SA, Fang D, Lian F, Zhang DD: Nrf2 is crucial to graft survival in a rodent model of heart transplantation. Oxid Med Cell Longev 2013;2013:919313.

43 Heiss E, Herhaus C, Klimo K, Bartsch H, Gerhauser C: Nuclear factor kappa B is a molecular target for sulforaphane-mediated anti-inflammatory mechanisms. J Biol Chem 2001;276:32008-32015. 